\title{
Daily reports of symptoms and negative affect: Not all symptoms are the same
}

\author{
SUSAN T. CHARLES ${ }^{1} \&$ DAVID M. ALMEIDA ${ }^{2}$ \\ ${ }^{1}$ Department of Psychology and Social Behavior, University of California, Irvine, and \\ ${ }^{2}$ Department of Human Development and Family Studies, The Pennsylvania State University, \\ 135 E. Nittany Ave Suite 405, State College, PA 16801
}

(Received 24 September 2003; in final form 17 March 2005)

\begin{abstract}
The interplay between state negative affect (SNA) and somatic symptoms is well-established in daily life, but the nature of the association is unclear. Questions remain regarding the role, if any, that SNA plays apart from trait negative affect (TNA), the direction of the association, and whether the relationship with SNA varies according to symptom type. Associations between three constellations of somatic symptoms and SNA were examined in adults $(N=781)$ queried on eight consecutive evenings. Inter- and intra-individual variation in temporal and concurrent associations were examined, with models including both state and trait negative affect. All symptoms were related to concurrent measures of SNA. Lagged associations varied by symptom type. No lagged analyses including respiratory symptoms were significant. Prior pain symptoms predicted SNA, and prior SNA predicted pain and gastrointestinal symptoms. TNA, however, mediated the association between prior pain symptoms and SNA.
\end{abstract}

Keywords: State negative affect, trait negative affect, somatic symptoms

\section{Introduction}

Somatic symptoms motivate health behavior, influence our daily lives, and reflect our physical well-being. They comprise the majority of adult illness experiences (Merrill \& Verbrugge, 1999), are the number one reason people seek physician care (Stone, 2000), and are associated with overall quality of daily life (Tveito, Passchier, Duivenvoorden \& Eriksen, 2004). Physicians recognize the utility of somatic symptoms and use them for diagnostic purposes (Daltroy, Larson, Eaton, Phillips \& Liang, 1999; Hughes, Edelman, Singer \& Chang, 1993). Despite their prevalence and importance, however, the "full picture of lifetime health is not known, especially about symptoms of daily life" 
(Verbrugge, 1985, p. 163). For this reason, researchers have examined factors associated with the experience of somatic symptoms, including affective well-being.

The association between somatic symptoms and affective processes is of both theoretical and practical importance. Theoretically, researchers disagree as to whether the association with somatic symptoms is limited to trait negative affect or includes transient affective experiences as well (Leventhal, Hansell, Diefenbach, Leventhal \& Glass, 1996; see review by Watson \& Pennebaker, 1989). On a practical level, both affective well-being and physical well-being are instrumental to the quality of daily life. In addition, understanding the nature and direction of the association between mood state and somatic complaints would help patients and therapists identify potential precursors to both somatic and affective distress.

The current study investigated current and reciprocal lagged associations between daily reports of somatic symptoms and negative affect in a national sample of adults ranging from 25 to 74 years-old. The short-term prospective daily diary design - following people over eight consecutive days - and the inclusion of both stable individual characteristics, e.g., trait negative affect, as well as daily experiences, i.e., state negative affect and symptom reports, enabled us to examine both inter- and intra-individual variation within the association between somatic symptoms and state negative affect.

\section{State negative affect and somatic symptoms: An artefact of trait negative affect?}

Researchers disagree as to whether self-reported state negative affect (SNA) and daily somatic complaints share a unique relationship beyond the influence of underlying trait negative affect (TNA). Watson and Pennebaker (1989) present evidence that TNA and SNA share similar relationships with symptom reports among community samples. According to their symptom perception hypothesis, people scoring high on TNA are more likely to report high levels of state negative affect and also to "perceive, overreact to, and/or complain about minor physical problems and sensations" (Watson \& Pennebaker, 1989, p. 249). TNA is highly stable and partially genetically determined (Pedersen, Plomin, McClearn \& Friberg, 1988; see review by McCrae et al., 2000). By definition, TNA does not fluctuate on a daily basis, and thus daily reports of SNA if only representative of TNA - should not covary with daily reports of somatic symptoms.

Other researchers find that SNAs and TNAs are different, albeit overlapping, measures that each provide unique information (Gross, Sutton \& Ketelaar, 1998). Moreover, both stable characteristics TNA and SNA (measured according to how people feel in the moment) are important determinants in the experience of somatic symptoms (Cohen et al., 1995; Leventhal et al., 1996). For example, daily SNA predicts next day's symptoms among younger and middle-aged adults (Cohen et al., 1995, but see Larsen \& Kasimatis, 1991). A growing literature has examined how psychosocial factors influence subjective well-being over time, which in turn is linked to health experience (see review by Charles \& Mavandadi, 2003; edited volume by Ryff \& Singer, 2001). On the basis of this premise, we hypothesize that SNA and somatic symptoms would have significant concurrent relationships and that they would predict each other over time, an influence that is not solely an artefact of TNA.

\section{Temporal association of SNA and somatic complaints}

Experiencing somatic symptoms may lead to greater SNA. Leventhal and his colleagues discuss bidirectional links between stress and illness experience, but emphasize the direction 
of poor health leading to greater negative affect (Leventhal, Patrick-Miller, Leventhal \& Burns, 1997). This directional model, referred to as the disability hypothesis, maintains that physical disease, disability, and the discomfort of poor health results in affective distress (Diefenbach, Leventhal, Leventhal \& Patrick-Miller, 1996). Although the disability hypothesis focuses on illness and disability, somatic symptoms among healthy adults may produce similar results. Somatic symptoms are often disruptive, and may have lasting effects on affective well-being. For example, among a sample of young, middle, and older adults, overall self-reported physical health status predicted current depressive symptoms three months later (Aneshensel, Frerichs \& Huba, 1984; but see Brown \& Moskowitz, 1997; Larsen \& Kasimatis, 1991).

Another model has been proposed to explain the reverse direction, where negative affect predicts somatic symptoms. The symptom perception hypothesis states that people high in TNA are more likely to perceive and report minor somatic symptoms (Watson \& Pennebaker, 1989). This model has been used to explain the association between SNA and symptoms, but views SNA as representative of underlying TNA. Other research extends this model to suggest that mood states alone predispose people to focus on internal physical sensations. Negative mood states have been associated with greater introspection (e.g., Nolen-Hoeksema, 1987), and people induced into negative mood states report greater number and severity of physical symptoms than people who have not undergone mood induction (Croyle \& Uretsky, 1987; Salovey \& Birnbaum, 1989). Thus, the symptom perception model may apply to transient mood states as well, although it is unclear whether negative affect is related to future, as opposed to only current, somatic symptoms.

Type of symptoms. The disability hypothesis specifies that discomfort brought on by physical health problems leads to negative affect. Therefore, the perception of any symptom, regardless of type, leads to greater negative affect. For this reason, we posited that all somatic symptoms predict later SNA. The ability of negative affect to predict later somatic complaints, however, may be contingent on symptom type. SNA has been related to increases in specific complaints in the research paradigm (e.g., Cohen et al., 1995), but it is unclear whether this finding will generalize to everyday experience. Symptoms more overt and easily detected by others may be less influenced by introspection and rumination compared to more systemic, diffuse symptoms. Thus, we predicted that less objectively measured symptoms, such as general pain and feelings of gastrointestinal upset, have a reciprocal association with negative affect, but questioned whether or not this reciprocal association would hold for more easily observed symptoms, such as coughs or fever.

\section{The present study}

The present study examined concurrent and lagged reciprocal associations between SNA and three different constellations of symptoms: pain, respiratory/flu, and gastrointestinal distress. First, we hypothesized that SNA and somatic symptoms would have significant concurrent relationships, similar to previous findings (e.g., Watson \& Pennebaker, 1989). We also hypothesized that these symptom constellations would have lagged associations with SNA from one day to the next. Concerning the direction of these associations, we predicted that for symptoms that are most ambiguous and systemic, i.e. pain and gastrointestinal upset, a reciprocal lagged association between negative affect and somatic symptoms exists. For flu and respiratory symptoms - symptoms often more overt and 
specific - we hypothesized that somatic symptoms predict next day's SNA, and we explored the ability of SNA to predict next day's symptoms.

We were also interested in the effect of TNA on these associations. Recognizing the significant relationship between TNA and symptoms (e.g., Costa \& McCrae, 1987; Johnson, 2003; Watson \& Pennebaker, 1989), we hypothesized that people higher on TNA would report more symptoms overall compared to people lower in TNA (main effect for TNA). Similarly, based on prior findings correlating TNA and SNA (e.g., Charles, Reynolds \& Gatz, 2001; Gross et al., 1998), we predicted a significant positive association between both measures of affect. We further hypothesized that these interrelationships would result in attenuating, but not eliminating, the concurrent and lagged associations between SNA and symptom report. We also explored whether current and prior symptoms predicted SNA to a greater extent among those scoring higher in TNA (moderation of TNA). This exploration was based on findings where people high in neuroticism were more reactive to stressors (Bolger \& Schilling, 1991). We were interested, therefore, in examining the possibility that people high in TNA may be more reactive to somatic symptoms as well.

Using an 8-day longitudinal diary method enabled us to conduct lag analysis to capture an entire week - a temporal structure used by individuals to structure their time and activities (Almeida \& McDonald, 1998; Larsen \& Kasimatis, 1991) - for adults spanning much of the adult age range. A one-day lag is a time frame used previously to understand daily processes of health and mood (e.g., Affleck, Tennen, Urrows \& Higgins, 1991; Bolger, DeLongis, Kessler \& Schilling, 1989; Watson, 1988). By using nightly interviews, we examined how reports of daily affective well-being (SNA) and somatic reports carry over to the next day. This prospective diary design allowed for analyses that examine, for example, whether a person was more likely to report a longer duration of somatic symptoms after days when he or she reported a longer duration of SNA compared to when he or she reported a shorter duration SNA. Finally, we included chronic illness as a control variable to insure that concurrent measures of somatic complaints were not merely reflecting differences in illness status between participants.

\section{Methods}

\section{Sample}

The sample was derived from the National Study of Daily Experiences (NSDE), a subset of participants from the Midlife in the United States Survey (MIDUS). The MIDUS is a nationally representative telephone-mail survey of 3032 people, aged 25-75 years, carried out in 1995-1996 (for descriptions of MIDUS, see Keyes \& Ryff, 1998; Mroczek \& Kolarz, 1998). Of the 1242 randomly chosen MIDUS respondents we attempted to contact, 1031 (562 women, 469 men) agreed to participate in the NSDE, yielding a response rate of $83 \%$. Over eight consecutive evenings, NSDE respondents completed short telephone interviews about their daily experiences, with all interviews taking place between March 1996 and April 1997. Initiation of interview flights was staggered across the day of the week. Although eight days is not long, intraclass correlations (the proportion of intra-individual variability to total variability) was 0.54 for negative affect and 0.45 for somatic symptoms, suggesting that the number of days provides enough intra-individual variability to capture within-person processes. Nightly interviews risk the possibility that engaging in self-monitoring may alter the normal fluctuations of daily experience, but this risk is less than that posed by studies asking for multiple interviews throughout the day (see discussion 
by Tennen, Suls \& Affleck, 1991). For a further description of the NSDE, see Almeida, Wethington \& Kessler (2002).

The NSDE subsample had similar demographic characteristics to the MIDUS main sample, but had a slightly greater percentage of women $(54.5 \%$ vs $51.5 \%$ of the samples, respectively), higher levels of education (62.3\% of the NSDE subsample had at least 13 years of education $v s \quad 60.8 \%$ of the MIDUS sample), and a smaller percentage of minority respondents: $90.3 \%$ were Caucasian, 5.9\% African-American and 3.8\% all other races, vs 87.8\% Caucasian, 6.8\% African-American, and 4.4\% all other races for the MIDUS sample. Participants averaged 47 years-old, and $38 \%$ of the respondents reported at least one minor living in the household. The average family income was between $\$ 50,000$ and $\$ 55,000$. Men were slightly older than women, had similar levels of education and were more likely to be married at the time of the study $(77 \%$ of the women $v s 85 \%$ of the men). Respondents for the present analysis were 781 participants who completed at least 7 consecutive interviews, thus eliminating 250 participants who were missing data for at least one day in between two other study days. This subsample of the NSDE did not differ from the entire NSDE sample across the aforementioned demographic variables, nor did they differ from the NSDE sample on the measure of TNA, $t(1,779)=1.34$.

\section{Measures}

State negative affect (SNA). The SNA measure was limited to symptoms of depression and anxiety, two emotions commonly used to define negative affect (e.g., Diefenbach et al., 1996; Leventhal et al., 1996; Mroczek \& Kolarz, 1998). A 6-item questionnaire asked participants how much of the time today did they feel: worthless; hopeless; nervous; restless or fidgety; that everything was an effort; and so sad that nothing could cheer you up. Participants rated their response on a 5-point scale from 0 (none of the time), to 4 (all of the time), and scores were summed across items. Presumably, the longer the duration of SNA throughout the day, the greater its potential influence on symptom reports. The scale was developed by Kessler and colleagues (2002) using item response models and factor analysis, which yielded a single factor structure representing current, general psychological distress (for complete information on the psychometric properties of the scale including the IRT analysis and validation across subsamples varying in age, ethnicity, socioeconomic status, and geographic location, refer to Kessler et al., 2002). Cronbach's alpha ranged from 0.75 to 0.85 across the eight administrations of this scale.

Trait negative affect (TNA). The TNA was assessed in the MIDUS survey using a short form of neuroticism developed specifically for this survey and validated in pilot studies (see Lachman \& Weaver, 1998). Participants responded to statements asking them, "Please indicate how well each of the following describes you" from not at all (0), to a lot (4), and their responses were summed. The adjectives were moody, worrying, nervous, and calm (reversed scored). Items were derived from other personality scales, including Goldberg's (1992) Big Five markers, and has been used in prior research to document associations between health and affect measures (Lachman \& Weaver, 1998; Mroczek \& Kolarz, 1998). Cronbach's alpha was 0.79 .

Daily somatic symptoms. Daily symptoms were measured using a shortened version of Larsen and Kasimatis' (1991) physical symptom checklist. For the purpose of this study, participants were asked about three constellations of symptoms: pain (headaches, 
backaches, and muscle soreness), gastrointestinal symptoms (poor appetite, nausea/upset stomach, constipation/diarrhea), and flu and respiratory symptoms (e.g., sore throat, runny nose; fever; chills; congestion). An additional category for "other" physical symptoms or discomforts was included, and coders blind to the hypotheses coded these responses $(\kappa=0.80)$ and, when appropriate, placed them into an existing category. The constellations of symptoms are the result of a factor analysis of daily symptom reports by younger adults (Larsen \& Kasimatis, 1991) and have been used previously to examine somatic complaints in adults ranging from 18 to 63 years-old (Brown \& Moskowitz, 1997).

We recognize that the labeling of gastrointestinal symptoms as more vague and diffuse, and the cold, flu and respiratory symptoms as more easily observed and more specific, is imperfect. Indeed, gastrointestinal symptoms may include vomiting and diarrhea, symptoms that can be monitored objectively. Similarly, cold, flu and respiratory symptoms may include symptoms difficult to measure, such as a sore throat with no voice loss, or symptoms that are more diffuse, such as chills. We, nonetheless, argue that the majority of transient, daily gastrointestinal and pain symptoms experienced by a non-patient population are more difficult to quantify by observers or the person who experiences these symptoms than flu and respiratory symptoms. Every night, respondents indicated the duration of their symptoms of aches/pain [pain]; gastrointestinal symptoms [GI]; and flu and respiratory symptoms [resp/flu] over the past $24 \mathrm{~h}$ using a 5-point scale anchored with (0) none of the time and (4) all of the time.

\section{Chronic illness}

Chronic illness, assessed in the MIDUS survey, represented an aggregation of 27 physical conditions for which participants checked as either having (1), or not having (0) (Marmot, Ryff, Bumpass, Shipley \& Marks, 1997). Examples of chronic conditions included in the list are asthma, bronchitis or emphysema; tuberculosis; diabetes or high blood sugar; high blood pressure or hypertension; ulcer; migraine headaches; arthritis, rheumatism, other bone or joint diseases; sciatica, lumbago, recurring backache; persistent skin trouble (e.g., eczema); thyroid disease; and hay fever. Items were summed and formed a measure of total number of chronic conditions.

\section{Analyses}

The method used to examine the lagged associations between health and affect within individuals over time was based on a multilevel, or hierarchical linear model (HLM) (Bryk \& Raudenbush, 1992) using SAS estimated by REML. These lagged models are akin to prospective and prospective change models (Larson \& Almeida, 1999) and allow for an examination of intra-individual variability. For example, the unique effects of a prior day symptom on current negative affect can be examined above the variance explained by average levels of SNA and current day symptoms. To exemplify these analyses is the following model:

$$
\begin{aligned}
\text { SNA }_{i t}= & b_{0}+b_{1} \text { TNA }_{i}+b_{2} \text { Symptom }_{i t}+b_{3} \text { Symptom }_{i t-1} \\
& +b_{5}\left(\text { TNA }_{i} \times \text { Symptom }_{i t-1}\right)+c_{i}+d_{i t},
\end{aligned}
$$

where $\mathrm{SNA}_{i t}$ represents the reported negative affect for respondent $i$ on day $t, \operatorname{Symptom}_{i t}$ indicates the symptom report on day $t$, Symptom $_{i t-1}$ indicates the symptom report on 
day $t-1, \mathrm{TNA}_{i}$ is the amount of TNA reported by respondent $i, \mathrm{TNA}_{i} \times \mathrm{Symptom}_{i t-1}$ is respondent $i$ 's score for the interaction effect of TNA and symptom on day $t, b_{1}$ through $b_{4}$ are coefficients defining the effects of TNA, symptom, and their interaction on SNA, $c_{i}$ is random variation in the individuals, and $d_{i t}$ is the random variation in the diary days.

A model where the slope is constrained to be equal across subjects (e.g., where the strength of the association between SNA and somatic symptoms is the same across all participants) was compared to one where the slopes are allowed to vary across individuals, e.g., where the strength of the association varies across individuals (for an explanation, refer to Bollen, 1989; Bryk \& Raudenbush, 1992). The model where the slopes varied produced a better fit for all the models in this article, as did models where the intercepts, e.g., mean level of daily symptoms or affect, were allowed to vary. Only the analyses allowing the slope and intercepts to vary are presented. Within all models, SNA and each of the somatic symptom measures were standardized around group means to reduce cross-level (i.e., daily measures vs stable measures) confounding (Kreft \& de Leeuw, 1998). This standardization also allows for easier comparisons across beta coefficients. Covariation between intercepts and slopes in the random portion of the model were estimated using unstructured error variances that were allowed to correlate with one another.

\section{Results}

Table I presents a description of the study variables averaged for the entire sample across all of the study days and again only on symptom days (i.e., days when respondents reported having at least some symptoms) to provide a better understanding of these data. For the entire sample, participants reported experiencing at least one physical symptom on a little more than half of the days they were interviewed (55.7\% of the total days). Across the three types of symptoms, they averaged $1.65(\mathrm{SD}=2.28)$ on the physical symptom scale for the days when any symptom was reported. A total of $12 \%$ reported no somatic symptom of any type. People reported at least some SNA on $42.7 \%(M=1.73, \mathrm{SD}=$ $3.56)$ of the days they were interviewed. The most frequently endorsed item was nervous ( $21 \%$ of the study days) and least endorsed item was worthless (4\% of study days).

Table I. Description and within-person correlations of daily variables.

\begin{tabular}{|c|c|c|c|c|c|c|c|c|}
\hline & \multicolumn{2}{|c|}{ All days } & \multicolumn{2}{|c|}{ Symptom days } & \multicolumn{4}{|c|}{ Within-person correlations ${ }^{\mathrm{b}}$} \\
\hline & Mean & SD & Mean & SD & Affect & Pain & Cold/Flu & GI \\
\hline Affect ${ }^{a}$ & 0.17 & $(0.36)$ & 0.49 & $(0.46)$ & 0.30 & 0.19 & 0.13 & 0.17 \\
\hline Pain & 0.80 & $(1.17)$ & 1.93 & $(1.05)$ & 0.24 & 0.23 & 0.13 & 0.10 \\
\hline Cold/Flu & 0.30 & $(0.84)$ & 2.02 & $(1.12)$ & 0.16 & 0.13 & 0.34 & 0.09 \\
\hline GI & 0.15 & $(0.57)$ & 1.77 & $(0.97)$ & 0.20 & 0.12 & 0.18 & 0.27 \\
\hline
\end{tabular}

$N=781$.

${ }^{\mathrm{a}}$ Affect $=$ state negative affect.

${ }^{\mathrm{b} C o e f f i c i e n t s ~ i n ~ b o l d ~ a r e ~ t h e ~ o n e ~ d a y ~ l a g g e d ~ a u t o ~ c o r r e l a t i o n s . ~ C o e f f i c i e n t s ~ b e l o w ~ t h e ~ d i a g o n a l ~ w e r e ~ c a l c u l a t e d ~ u s i n g ~}$ all study days $(N=5995)$. Coefficients above the diagonal were calculated using study days when no symptoms were reported the previous day $(N=2005)$.

Note. Pain $=$ aches/pain; Cold/Flu = cold, flu, and respiratory symptoms; GI = gastrointestinal distress. These days were comprised of the weekly interviews from 781 participants. 
Table II. Between-persons correlations for the variables used for the hierarchical linear models.

\begin{tabular}{|c|c|c|c|c|c|c|c|}
\hline & Affect & Pain & Cold/Flu & GI & Age & Gender & Chronic illness \\
\hline Pain & $0.41^{\star}$ & & & & & & \\
\hline Cold/Flu & $0.24^{\star}$ & $0.22^{\star}$ & & & & & \\
\hline GI & $0.34^{\star}$ & $0.29^{\star}$ & $0.24^{\star}$ & & & & \\
\hline Age & $-0.10^{\star}$ & -0.02 & -0.04 & $-0.12^{\star}$ & & & \\
\hline Gender & $0.08^{\star}$ & $0.09^{\star}$ & 0.04 & $0.09^{\star}$ & 0.00 & & \\
\hline Chronic illness & $0.15^{\star}$ & $0.21^{\star}$ & $0.13^{\star}$ & $0.16^{\star}$ & $0.11^{\star}$ & $0.06^{\star}$ & \\
\hline TNA & $0.29^{\star}$ & $0.17^{\star}$ & $0.08^{\star}$ & $0.15^{\star}$ & $-0.16^{\star}$ & $0.11^{\star}$ & $0.27^{\star}$ \\
\hline
\end{tabular}

Note. Cold/flu = cold, flu, and respiratory symptoms; GI = gastrointestinal distress. $N=781 .{ }^{\star} p<0.01$.

Six percent of the sample reported no SNA, i.e. reporting 0 on all questions about daily SNA at every time point, and no somatic complaints throughout the study.

Table I also provides the within-person lagged correlations among the study variables across all of the diary days (below the diagonal) and on study days when no symptoms were reported on the previous day (the upper diagonal). Correlations were calculated using a series of bivariate HLMs on within-person standardized scores (i.e., creating $z$ scores for each person-day based upon his or her daily reports). Coefficients above the diagonal show more attenuated associations with SNA when controlling for the symptoms reports of the prior day to provide a picture of the lagged associations free from proximal influences of the same symptom from the prior day. The diagonal of the matrix indicates a modest degree of across time autocorrelation among the variables.

Table II provides the between persons associations among the study variables used in the analyses below for the entire sample across all measurement time points. For the variables measured more than once, the within-person average across all days was calculated, and this score was used in the correlation matrix. Demographics were examined in relation to both symptoms and negative affect for the between-subjects associations. Age, chronic illness and gender were related to the affect variable, and for this reason they were included as covariates in the analyses. People who were older reported less negative affect aggregated across all the time points, but more chronic illnesses. In addition, people with more chronic illness also reported greater negative affect and more symptoms. Finally, women were more likely to report greater averaged SNA throughout the day and slightly more somatic symptoms.

\section{Testing the concurrent and reciprocal association between symptoms and SNA}

Pain symptoms and SNA. HLM analyses assessed the temporal relations between state affect and pain. In the first model, prior day pain was entered into an analysis to predict current SNA. In a second model, current day pain was also entered to control for the potential carryover of pain from one day to the next. The first two rows in Table III provide these results. Both current and prior day pain significantly predicted current SNA. The coefficient from this model suggests that a unit increase in prior day pain predicts a 0.06 increase in current SNA. In addition, current and prior day pain accounts for $24 \%$ of the Level 1 (i.e., within person) variance in affect.

The Level 2 variables including age, gender, chronic illness and TNA were entered next. Taken together, these variables accounted for $24 \%$ of the Level 2 (i.e., between-persons) variance in SNA. Importantly, the relationships between both current and prior pain with current SNA were significant even after the inclusion of these Level 2 variables. Results indicate that people are more likely to report greater SNA the day after they have 
Table III. HLM results of current and prior day's somatic symptoms predicting current SNA.

\begin{tabular}{|c|c|c|}
\hline & \multicolumn{2}{|c|}{$\begin{array}{l}\text { Outcome: Current state } \\
\text { negative affect (SNA) }\end{array}$} \\
\hline & $B$ & Standard error \\
\hline \multicolumn{3}{|l|}{ Predictors: Pain } \\
\hline Current day pain & $0.18^{\star \star}$ & 0.02 \\
\hline Prior day pain & $0.06^{\star \star}$ & 0.01 \\
\hline Proportion of Level 1 variance & 0.24 & \\
\hline \multicolumn{3}{|l|}{ Predictors: Pain (with covariates) } \\
\hline Current day pain & $0.17^{\star \star}$ & 0.02 \\
\hline Prior day pain & $0.04^{\star \star}$ & 0.01 \\
\hline Gender & 0.02 & 0.01 \\
\hline Age & -0.01 & 0.01 \\
\hline Chronic illness & $0.05^{\star}$ & 0.02 \\
\hline Trait negative affect (TNA) & $0.21^{\star \star}$ & 0.02 \\
\hline TNA $\times$ Current day pain & $0.08^{\star \star}$ & 0.02 \\
\hline TNA $\times$ Prior day pain & $0.03^{\star}$ & 0.01 \\
\hline Proportion of Level 2 variance & 0.21 & \\
\hline \multicolumn{3}{|l|}{ Predictors: GI } \\
\hline Current day GI & $0.17^{\star \star}$ & 0.03 \\
\hline Prior day GI & 0.02 & 0.01 \\
\hline Proportion of Level 1 variance & 0.21 & \\
\hline \multicolumn{3}{|l|}{ Predictors: GI (with covariates) } \\
\hline Current day GI & $0.16^{\star \star}$ & 0.03 \\
\hline Prior day GI & 0.02 & 0.01 \\
\hline Gender & 0.05 & 0.04 \\
\hline Age & -0.01 & 0.01 \\
\hline Chronic illness & $0.07^{\star}$ & 0.03 \\
\hline Trait negative affect (TNA) & $0.21^{\star \star}$ & 0.02 \\
\hline TNA $\times$ Current day GI & $0.07^{\star}$ & 0.03 \\
\hline Proportion of Level 2 variance & 0.21 & \\
\hline \multicolumn{3}{|l|}{ Predictors: Resp/flu } \\
\hline Current day Resp/flu & $0.12^{\star \star}$ & 0.02 \\
\hline Prior day Resp/flu & 0.02 & 0.01 \\
\hline Proportion of Level 1 variance & 0.16 & \\
\hline \multicolumn{3}{|c|}{ Predictors: Resp/flu (with covariates) } \\
\hline Current day Resp/flu & $0.11^{\star \star}$ & 0.02 \\
\hline Prior day Resp/flu & 0.02 & 0.01 \\
\hline Gender & 0.05 & 0.04 \\
\hline Age & -0.01 & 0.01 \\
\hline Chronic illness & $0.06^{\star}$ & 0.03 \\
\hline Trait negative affect (TNA) & $0.24^{\star \star}$ & 0.02 \\
\hline TNA $\times$ Current day Resp/flu & $0.04^{\star}$ & 0.02 \\
\hline Proportion of Level 2 variance & 0.20 & \\
\hline
\end{tabular}

Note. Resp/flu $=$ respiratory and cold/flu symptoms; GI $=$ symptoms of gastrointestinal distress; TNA $=$ trait negative affect. ${ }^{\star} p<0.01,{ }^{\star \star} p<0.0001$. Results are based on the following model:

Level 1: AFFECT $_{i t}=a_{0 i}+a_{1 i}$ SYMPTOM $_{i t-1}+\mathrm{a}_{2 i}\left(\mathrm{SYMPTOM}_{i t-1}\right)+e_{i t}$. Level 2: $a_{0 i}=B_{00}+B_{01}(\mathrm{AGE})+B_{02}$ (Gender) $+B_{03}$ (Chronic Health) $+B_{04}$ (Trait Negative Affect) $+d_{i}$, $a_{1 i}=B_{10}+B_{11}$ (AGE) $+B_{12}$ (Gender) $+B_{13}($ Chronic Health $)+B_{14}$ (Trait Negative Affect) $+g_{i}$. $a_{2 i}=B_{20}+B_{21}(\mathrm{AGE})+B_{22}($ Gender $)+B_{23}($ Chronic Health $)+B_{24}$ (Trait Negative Affect) $+g_{i}$. 


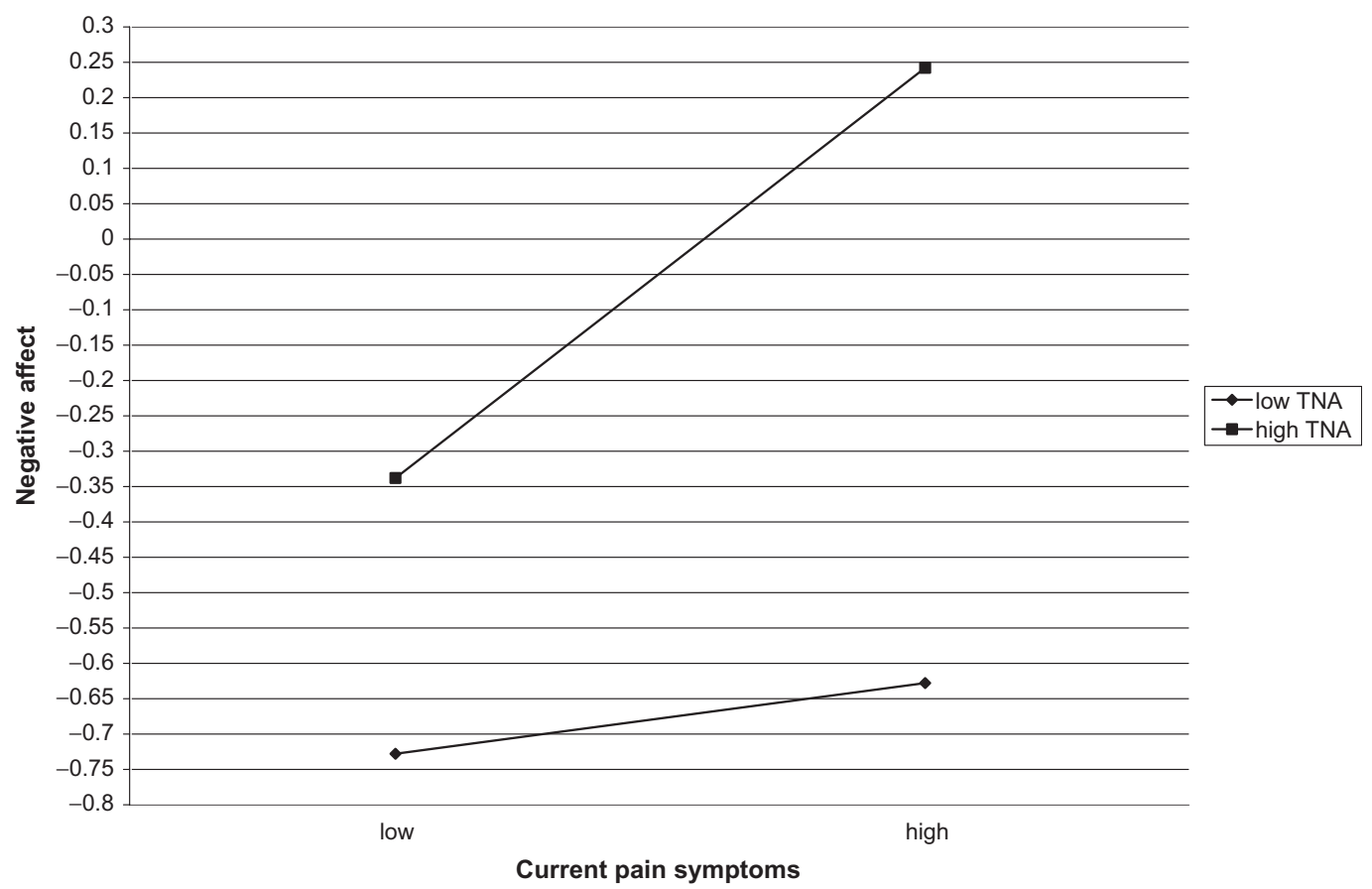

Figure 1. The interaction between concurrent trait negative affect and current pain symptoms in predicting state negative affect. Note. The values of all variables were centered within-person, resulting in $Z$ scores.

experienced pain symptoms even when controlling for current pain and stable demographic and personality characteristics. People with more chronic illnesses and higher levels of TNA were also more likely to report SNA. Furthermore, significant interactions between TNA (Level 2 variable) and current pain (Level 1 variable) as well as prior pain (Level 1 variable) suggest that the associations between pain symptoms and SNA is stronger for people with higher levels of TNA. Figure 1 illustrates the shape of this interaction for current symptoms.

To examine the reverse temporal association, an HLM equation where prior day SNA predicted current pain symptoms was significant even after the inclusion of current day SNA, accounting for $18 \%$ of the Level 1 variance in pain symptoms (see Table IV). However, prior SNA was not significant after the inclusion of the Level 2 variables. People with more chronic illness and higher levels of TNA were more likely to report symptoms, accounting for $24 \%$ of the Level 2 variance. The interaction between TNA with prior SNA was not significant, revealing that people higher in TNA were not likely to report greater pain symptoms after experiencing SNA than people low in TNA.

Gastrointestinal (GI) symptoms and SNA. Similar to previous research, GI symptoms shared a significant concurrent association with SNA and TNA (Tables I and II). In a test of the hypothesized reciprocal lagged associations, our hypothesis was not confirmed. Prior day's GI symptoms did not significantly predict current SNA after including current day GI symptoms (see Table III). Including the Level 2 variables age, gender, chronic illnesses, and TNA revealed that people with more chronic illnesses and those high in 
Table IV. HLM results of current and prior day state negative affect (SNA), age, gender, chronic illness and trait negative affect predicting current somatic symptoms.

\begin{tabular}{|c|c|c|c|c|c|c|}
\hline \multirow[b]{2}{*}{ Outcomes: } & \multicolumn{2}{|c|}{ Current pain } & \multicolumn{2}{|c|}{ Current GI } & \multicolumn{2}{|c|}{ Current Resp/flu } \\
\hline & $B$ & Standard error & $B$ & Standard error & $B$ & Standard error \\
\hline \multicolumn{7}{|l|}{ Predictors SNA: } \\
\hline Current day SNA & $0.16^{\star \star}$ & 0.02 & $0.21^{\star \star}$ & 0.03 & $0.10^{\star \star}$ & 0.04 \\
\hline Prior day SNA & $0.04^{\star}$ & 0.01 & $0.08^{\star \star}$ & 0.02 & 0.01 & 0.02 \\
\hline Proportion of level 1 variance & & 0.18 & & 0.23 & & 0.08 \\
\hline \multicolumn{7}{|l|}{ Predictors SNA (with covariates): } \\
\hline Current day SNA & $0.17^{\star \star}$ & 0.01 & $0.20^{\star \star}$ & 0.06 & $0.09^{\star}$ & 0.02 \\
\hline Prior day SNA & 0.01 & 0.01 & $0.07^{\star}$ & 0.03 & 0.03 & 0.02 \\
\hline Gender & $0.08^{\star}$ & 0.04 & $0.11^{\star \star}$ & 0.04 & 0.01 & 0.01 \\
\hline Age & 0.01 & 0.01 & -0.01 & 0.01 & -0.01 & 0.01 \\
\hline Chronic illness & $0.16^{\star \star}$ & 0.03 & $0.12^{\star}$ & 0.03 & $0.10^{\star}$ & 0.04 \\
\hline Trait negative affect (TNA) & $0.09^{\star \star}$ & 0.03 & 0.03 & 0.03 & 0.02 & 0.02 \\
\hline Proportion of level 2 variance & & 0.21 & & 0.27 & & 0.04 \\
\hline
\end{tabular}

Note. $\mathrm{SNA}=$ state negative affect; $\mathrm{TNA}=$ trait negative affect. ${ }^{\star} p<0.01,{ }^{\star \star} p<0.0001$. Results are based on the following model:

Level 1: SYMPTOM $_{i t}=a_{0 i}+a_{1 i}\left(\mathrm{AFFECT}_{i t}\right)+a_{2 i}\left(\mathrm{AFFECT}_{i t-1}\right)+e_{i t}$.

Level 2: $a_{0 i}=B_{00}+B_{01}$ (AGE) $+B_{02}($ Gender $)+B_{03}($ Chronic Health $)+B_{04}$ (Trait Negative Affect) $+d_{i}$,
$a_{1 i}=B_{10}+B_{11}(\mathrm{AGE})+B_{12}($ Gender $)+B_{13}$ (Chronic Health) $+B_{14}$ (Trait Negative Affect)
$+g_{i}$.

TNA were more likely to report SNA. The interaction between TNA and GI symptoms was significant, revealing that the association between current GI symptoms and current SNA is stronger for people high in TNA. The shape of the interaction is the same as that for pain, illustrated in Figure 1.

In the reverse direction, however, prior day's SNA predicted GI symptoms alone, after the inclusion of current day's SNA, and after the inclusion of the Level 2 variables (see Table IV). Women and respondents with more chronic illness also reported more GI symptoms. Interestingly, both current and prior day SNA predicted GI distress, but TNA was not significant $(B=0.02)$, and the test of moderation of TNA was not significant.

Cold, respiratory and flu symptoms [resp/flu] and SNA. Resp/flu symptoms shared a concurrent association with both SNA and TNA (Tables I and II). Prior day's resp/flu symptoms did not, however, predict SNA after current day's cold and flu symptoms were entered in the analysis (Table III). Similar to the other symptoms, TNA again moderated the current resp/flu symptom and affect association in the same manner as displayed in Figure 1, where those high in TNA had an even stronger association between current resp/flu symptoms and SNA.

Unlike the more ambiguous pain and GI symptoms, resp/flu symptoms were not predicted by prior SNA in an investigation of the reverse direction (Table IV). Results indicate that people are more likely to report greater SNA on the day they have experienced resp/flu symptoms but there is no evidence for across day associations. TNA did not moderate this concurrent relationship.

Comparing across symptom constellations. Of the three symptom constellations, only prior pain predicted current negative affect (see Table III). To compare the strengths of the lagged associations with SNA between symptoms, the standardized beta weights for each 
symptom from each analysis underwent a Fisher $r$-to- $z$ transformation and then were compared using an analysis recommended by Meng, Rosenthal and Rubin (1992). The coefficient for prior day pain was significantly greater than the coefficient for GI symptoms, $Z=2.31, p<0.01$, and $\mathrm{resp} / \mathrm{flu}$ symptoms, $Z=2.35, p<0.01$. When the additional covariates were entered in the analysis of pain predicting SNA, the standardized beta weight was still significant $(B=0.04)$, but it was no longer significantly different from those of either GI distress, $Z=1.15$, or resp/flu symptoms, $Z=0.90$.

For the ability of prior SNA to predict current symptoms, initial models with only prior and current SNA predicting symptoms revealed that prior day SNA significantly predicted GI symptoms $(B=0.08)$ and pain symptoms $(B=0.04)$, but not resp/flu symptoms $(B=0.01)$. Comparing across these beta coefficients, prior day SNA predicted GI symptoms to a significantly greater degree than it did for pain, $Z=2.31, p<0.01$, and resp/flu symptoms, $Z=4.23, p<0.01$. After the covariates were entered, prior day SNA significantly predicted GI symptoms $(B=0.07)$, but not pain $(B=0.04)$ or resp/flu symptoms $(B=0.01)$. In addition, the association between prior day SNA and GI symptoms was significantly greater than that of prior SNA predicting either pain, $Z=3.46, p<0.01$, or resp/flu, $Z=3.63, p<0.01$.

\section{Discussion}

Researchers have studied temporal relationships between affect variables and health status in studies assessing levels of functional impairment (e.g., Lieberman et al., 1999) and chronic pain (e.g. Affleck, Tennen, Urrows \& Higgins, 1994) among patient populations. We were interested in examining these associations among healthy adults to examine how seemingly transient experiences of health and affective well-being may have a greater effect on daily life than their definitions imply. Only a handful of studies have examined causal directions in the symptom/affect relationship among relatively healthy adults, and few of these have tested both directions simultaneously or looked at different types of symptoms in the same study (Larsen \& Kasimatis, 1991). In the present study, we examined concurrent and day-to-day lagged reciprocal associations between SNA and three constellations of symptom reports. As hypothesized, all symptom groups were related to concurrent measures of SNA. We further hypothesized that lagged associations would exist, and we made specific hypotheses concerning the direction of the lagged associations based on symptom type. Associations between SNA and symptoms did vary by symptom type, yet these differences were only partially consistent with the hypotheses.

Prior day symptoms influencing current day SNA. Based on the disability hypothesis, we predicted that prior day symptoms, regardless of type, would lead to greater frequency of current SNA. This hypothesis was confirmed only for pain symptoms. Greater duration of pain on the prior day predicted greater reports of SNA, a significant finding, albeit attenuated, after controlling for TNA. No other symptom constellation, i.e. GI or cold/ flu, showed the same effect. These results suggest that more transient experiences of pain exert prolonged effects on SNA, and more so than other symptom types. Pain may be a symptom that people remember more strongly, and more negatively, than other symptoms, and hence its lagged effect on SNA.

Alternative explanations using physiological mechanisms are speculative, given the absence of physiological data in this study. One possibility is that neurobiological processes shared by both pain and emotion experiences are influenced by the pain experience 
(e.g., O'Regan \& Clow, 2004). Physical resources have been depleted as a result of the pain experience, and emotional experience may suffer as a result (for a detailed description of this hypothesis, refer to Leventhal et al., 1997). Affect is included in pain's definition (International Association for the Study of Pain, 1986), and therefore pain may influence emotional experience to a greater extent than other types of symptoms.

Prior day SNA influencing current day symptoms. We had hypothesized, based on the symptom perception hypothesis, that more ambiguous symptoms would be predicted by prior day SNA, but not more overt symptoms. Pain and GI symptoms are symptoms that are largely determined by subjective ratings, both include diffuse, ambiguous symptoms, and in this study, both were associated with concurrent SNA and with TNA. Intra-individual variation revealed that prior day SNA predicted GI symptoms and pain symptoms, although pain was not significant once TNA was entered. Findings from the present study suggest that the symptom perception hypothesis can be applied to the effects of both concurrent and lagged SNA on GI symptoms and pain. Moreover, TNA was not significant in the model with GI symptoms, underscoring the importance of SNA for this particular symptom constellation. Findings including the GI symptoms are consistent with those of Leventhal and colleagues (1996), showing that SNA - measured by asking people how they feel in the moment -, predicted somatic complaints six months later in a sample of older adults and was a greater predictor than TNA. Findings are also consistent to those of Brown and Moskowitz (1997) who found that prior SNA, but not TNA, predicted later symptom reports throughout the course of the day. Similar to our results, Brown and Moskowitz (1997) also found very small effects, but noted that they were similar to the effect size of other established risk factors of physical conditions studied in health psychology, such as cigarette smoking.

For the more specific, and often less ambiguous, symptoms of resp/flu, prior SNA was not a significant predictor. Perhaps the reliance on more easily measured criteria, such as number of coughs or amount of nasal discharge, provides a greater protection against transient SNA influencing symptom amplification (as would be hypothesized by the symptom perception hypothesis).

Again, any explanations regarding physiological processes are not addressed in this study. Nonetheless, possible explanations should be considered. The psychosomatic hypothesis predicts a causal link between the experience of affective distress and somatic symptoms. Scientists proposing this hypothesis have suggested that stressful situations and negative emotional experiences produce physiological changes that predispose people to chronic illnesses or exacerbate existing conditions (see review by Friedman \& Booth-Kewley, 1987). Studies have found that negative mood is associated with sympathetic nervous system activation (e.g., Levenson, 1992) and changes in immune functioning (e.g., Futterman, Kemeny, Shapiro, Polonsly \& Fahey, 1992; see review by Herbert \& Cohen, 1993). Across much longer lag times, younger, middle-aged, and older participants with initially high depressive mood scores were more likely to report having experienced physical illness episodes in the intervening three months compared to those with lower scores (Aneshensel et al., 1984). It is unclear whether physiological changes would have rapid effects that cause fluctuations in symptoms from day to day. Again, the absence of physiological data in this study leaves the psychosomatic hypothesis an untested possibility.

The role of TNA. As hypothesized, TNA positively correlated with somatic complaints, consistent with prior research (e.g., Watson \& Pennebaker, 1989), and with SNA, again 
consistent with prior research (Gross et al., 1998; Larsen \& Ketelaar, 1991). Furthermore, the findings that TNA eliminated the association between prior SNA and pain symptoms is similar to the findings of Affleck, Tennen, Urrows and Higgins (1992), who reported that TNA reduced the association between daily pain and mood reports among people with rheumatoid arthritis. Regarding moderating effects, people with higher TNA who experienced any somatic complaints were more likely to report greater concurrent SNA compared to those with lower TNA. In other studies, people higher in TNA reacted more strongly to negative events (e.g., Bolger \& Schilling, 1991; Gross et al., 1998) and the current findings suggest that this phenomenon can be applied to the immediate experience of somatic symptoms as well.

In contrast, Larsen and Kasimatis (1991) found no influence of TNA in the association between the frequency of reporting somatic symptoms and SNA. They used a younger sample, and the role of TNA with somatic symptoms and affect may change with age. Middle-age is a time when the onset of chronic diseases and life threatening conditions are more likely to occur. Therefore, a person who scores high on TNA may not focus their worries on somatic symptoms when they are younger; but, at an older age, this same person may view physical symptoms with more anxiety and concern - a forewarning of an impending health threat. Interestingly, TNA did not interact with SNA to predict greater symptom reporting, similar to findings from a study examining people with a chronic pain condition (Affleck et al., 1992).

Strengths and limitations. Clearly, questions remain regarding the relationship between SNA and somatic complaints. Regarding measurement issues, these questions were self-reported and subject to potential response biases and inaccuracies that may be influencing the associations. In addition, this study focused on the phenomenology of symptoms and negative affect, and not actual illness. Questions regarding possible physiological mechanisms connecting TNA and SNA to these symptoms, as posited in theories of psychosomatic illnesses (see review by Friedman \& Booth-Kewley, 1987; Leventhal et al., 1997), will have to be explored in future studies. In addition, by focusing on the affective symptoms of depression and anxiety, other negative emotions implicated in prior health research, specifically shame and anger/hostility, were not included. Furthermore, somatic symptoms were confined to responses from three broad questions, and greater sensitivity to types of illness would allow for more refined analyses. These limitations were the byproduct of the use of telephone interviews, as opposed to larger surveys or medical examinations. Telephone interviews allowed us to ask open-ended questions to increase the probability that any somatic symptom experienced would be documented. In addition, the telephone paradigm allowed us to use a large, national sample to study naturally occurring symptoms and SNA. Using a sample with naturally occurring symptoms meant that not all symptoms were experienced by everyone - a problem that limited power - but increased the generalizability of the findings.

Other limiting factors concern having only 8 days of measurement, which increases the problems of multicollinearity among the daily measures. This multicollinearity limited us to examining one-day lags. Different symptoms may have longer lags, not tested in this current study. Despite the one-day lag limitation, including prior SNA and current SNA in the same analysis led to a stringent test of the unique effects of prior SNA, which protected against overestimating potential effects (Type I errors). The disadvantage of having a limited number of days was offset by the large sample size, thus allowing us 
to examine potential covariates and interacting factors, such as TNA. In addition, the use of a large national sample was an advantage over relying on reports of somatic complaints from small convenience samples, e.g. college students.

Implications. The focus of the article is predominantly theoretical and suggests avenues for future research into understanding associations between SNA and different types of somatic symptoms. The SNA/symptom relationship, however, has implications for practitioners as well. Further studies have to examine this question more thoroughly before concrete suggestions can be made to patients regarding their transient, somatic complaints. At this time, we tentatively speculate that clinicians working with people who experience transient pain can help clients understand that daily symptoms of pain may influence their current and later SNA. Therefore, after first identifying and medically treating the possible causes of somatic complaints, people may benefit from learning how to distract themselves from these symptoms to reduce SNA. In addition, helping people identify their GI symptoms and quantify them may also help to attenuate or even eliminate the spillover effects of symptoms on SNA from one day to the other.

\section{Conclusion}

The current study examined the question of how affects - SNA and TNA - each contribute to daily somatic complaints. Examining these influences yields a complex relationship. All symptoms are not the same, nor do they have a similar relationship with SNA. In the argument for whether or not feelings influence perception of somatic symptoms or vice versa, the answer is that the predictive power of each factor depends on the somatic symptoms measured. One model cannot explain all associations, as patterns vary according to the type of emotional experience examined - either SNA or TNA - as well as the constellation of symptoms studied. For all symptoms, daily symptom reports correlated with daily negative affects. These findings suggest that even minor daily complaints create a spillover effect into the affective experience of their daily lives. For lagged associations between daily negative affect and somatic complaints, findings depend on the types of symptoms rather than aggregated overall symptom reports. By examining these daily processes, we are slowly gaining new information into the associations between daily perceived experiences of both physical and affective well-being.

\section{Acknowledgements}

The research reported in this article was supported by grants from the MacArthur Foundation Research Network on Successful Midlife Development and the National Institute on Aging (AG16731). The authors wish to thank Melanie Horn Mallers for her research assistance and editing comments.

\section{References}

Affleck, G., Tennen, H., Urrows, S., \& Higgins, P. (1991). Individual differences in the day-to-day experience of chronic pain: A prospective daily study of rheumatoid arthritis patients. Health Psychology, 10, 419-426.

Affleck, G., Tennen, H., Urrows, S., \& Higgins, P. (1992). Neuroticism and the pain-mood relation in rheumatoid arthritis: Insights from a prospective daily study. Fournal of Consulting and Clinical Psychology, 60, 119-126. 
Affleck, G., Tennen, H., Urrows, S., \& Higgins, P. (1994). Person and contextual features of daily stress reactivity: Individual differences in relations of undesirable daily events with mood disturbance and chronic pain intensity. Fournal of Personality \& Social Psychology, 66, 329-340.

Almeida, D. M., \& McDonald, D. A. (1998). Weekly rhythms of parent's work stress, home stress, and parent adolescent tension. In A. C. Crouter \& R. Larsen (Eds), Temporal rhythms in adolescence: Clocks, calendars and the coordination of daily life (pp. 53-67). San Francisco, CA: Jossey-Bass.

Almeida, D. M., Wethington, E., \& Kessler, R. C. (2002). The Daily Inventory of Stressful Experiences (DISE): An interview-based approach for measuring daily stressors. Assessment, 9, 41-55.

Aneshensel, C. S., Frerichs, R. R., \& Huba, G. J. (1984). Depression and physical illness: A multiwave, nonrecursive causal model. Fournal of Health and Social Behavior, 25, 350-371.

Bolger, N., DeLongis, A., Kessler, R. C., \& Schilling, E. A. (1989). Effects of daily stress and negative mood. fournal of Personality and Social Psychology, 57, 808-818.

Bolger, N., \& Schilling, E. A. (1991). Personality and the problems of everyday life: The role of neuroticism in exposure and reactivity to daily stressors. Fournal of Personality, 59, 355-386.

Bollen, K. (1989). Structural equations with latent variables. New York: John Wiley and Sons.

Brown, K. W., \& Moskowitz, D. S. (1997). Does unhappiness make you sick? The role of affect and neuroticism in the experience of common physical symptoms. Fournal of Personality and Social Psychology, 72, 907-917.

Bryk, A. S., \& Raudenbush, S. W. (1992). Hierarchical linear models. Newbury Park, California: Sage Publications.

Charles, S. T., \& Mavandadi, S. (2003). Relationships and health across the life span. In F. Lang \& K. Fingerman (Eds), Growing together: Personal relationships across the life span (pp. 240-267). New York: Cambridge University Press.

Charles, S. T., Reynolds, C., \& Gatz, M. (2001). Age-related differences and change in positive and negative affect over twenty-five years. Fournal of Personality and Social Psychology, 80, 136-151.

Cohen, S., Doyle, W. J., Skoner, D. P., Fireman, P., Gwaltney, J. M., \& Newsom, J. T. (1995). State and trait negative affect as predictors of objective and subjective symptoms of respiratory viral infections. Fournal of Personality and Social Psychology, 68, 159-169.

Costa, P. T., \& McCrae, R. R. (1987). Neuroticism, somatic complaints, and disease: Is the bark worse than the bite? Special Issue: Personality and physical health. Fournal of Personality, 55, 299-316.

Croyle, R. T., \& Uretsky, M. B. (1987). Effects of mood on self-appraisal of health status. Health Psychology, 6, 239-253.

Daltroy, L. H., Larson, M. G., Eaton, H. M., Phillips, C. B., \& Liang, M. H. (1999). Discrepancies between self-reported and observed physical function in the elderly: The influence of response shift and other factors. Social Science \& Medicine, 48, 1549-1561.

Diefenbach, M. A., Leventhal, E. A., Leventhal, H., \& Patrick-Miller, L. (1996). Negative affect relates to cross-sectional but not longitudinal symptom reporting: Data from elderly adults. Health Psychology, 15, 282-288.

Friedman, H. S., \& Booth-Kewley, S. (1987). The “disease-prone personality": A meta-analytic view of the construct. American Psychologist, 42, 539-555.

Futterman, A. D., Kemeny, M. E., Shapiro, D. P., Polonsky, W., \& Fahey, J. L. (1992). Immunological variability associated with experimentally-induced positive and negative affective states. Psychological Medicine, 22, 231-238.

Goldberg, L. R. (1992). The development of markers for the Big-Five factor structure. Psychological Assessment, 4, $26-42$.

Gross, J. J., Sutton, S. K., \& Ketelaar, T. (1998). Relationship between affect and personality: Support for the affect-level and affective-reactivity view. Personality and Social Psychology Bulletin, 24, 279-288.

Herbert, T. B., \& Cohen, S. (1993). Stress and immunity in humans: A meta-analytic review. Psychosomatic Medicine, 55, 364-379.

Hughes, S. L., Edelman, P. L., Singer, R. H., \& Chang, R. W. (1993). Joint impairment and self-reported disability in elderly persons. Fournals of Gerontology, 48, S84-S92.

Johnson, M. (2003). The vulnerability status of neuroticism: Over-reporting or genuine complaints? Personality and Individual Differences, 35, 877-887.

Kessler, R. C., Andrews, G., Colpe, L., Hiripi, E., Mroczek, D. K., Normand, S.-L., et al. (2002). Short screening scales to monitor population prevalences and trends in nonspecific psychological distress. Psychological Medicine, 32, 959-976.

Keyes, C. L. M., \& Ryff, C. D. (1998). Generativity in adult lives: Social structural contours and quality of life consequences. In D. P. McAdams \& E. de St. Aubin (Eds), Generativity and adult development: How and why we care for the next generation (pp. 227-263). Washington, DC: American Psychological Association.

Kreft, I., \& de Leeuw, J. (1998). Introducting multilevel modeling. Thousand Oaks, CA: Sage.

Lachman, M., \& Weaver, S. L. (1998). Sociodemographic variations in the sense of control by domain: Findings from the MacArthur studies of midlife. Psychology \& Aging, 13, 553-562.

Larsen, R. J., \& Kasimatis, M. (1991). Day-to-day physical symptoms: Individual differences in the occurrence, duration, and emotional concomitants of minor daily illnesses. Fournal of Personality, 59, 387-423. 
Larsen, R. J., \& Ketelaar, T. (1991). Personality and susceptibility to positive and negative emotional states. Fournal of Personality and Social Psychology, 61, 132-140.

Larson. R. W., \& Almeida, D. M. (1999). Emotional transmission in the daily lives of families: A new paradigm for studying family process. Fournal of Marriage $\mathcal{E}$ the Family, 61, 5-20.

Levenson, R. W. (1992). Autonomic nervous system differences among emotions. Psychological Science, 3, 23-27.

Leventhal, E. A., Hansell, S., Diefenbach, M., Leventhal, H., \& Glass, D. C. (1996). Negative affect and self-reports of physical symptoms: Two longitudinal studies of older adults. Health Psychology, 15, $282-288$.

Leventhal, H., Patrick-Miller, L., Leventhal, E. A., \& Burns, E. A. (1997). Does stress-emotion cause illness in elderly people? In K. W. Schaie \& M. P. Lawton (Eds), Annual review of gerontology and geriatrics, Vol. 17: Focus on emotion and adult development (pp. 138-184). New York: Springer Publishing Co.

Lieberman, D., Galinsky, D., Fried, V., Grinshpun, Y., Mytlis, N., Tylis, R., et al. (1999). Geriatric Depression Screening Scale (GDS) in patients hospitalized for physical rehabilitation. International fournal of Geriatric Psychiatry, 14, 549-555.

Marmot, M., Ryff, C. D., Bumpass, L. L., Shipley, M. \& Marks, N. F. (1997). Social inequalities in health: Next questions and converging evidence. Social Science and Medicine, 44, 901-910.

McCrae, R. R., Costa, P. T., Ostendorf, F., Angleitner, A., Hrebickova, M., Avia, M. D., et al. (2000). Nature over nurture: Temperament, personality, and life span development. Fournal of Personality E Social Psychology, 78, 173-186.

Meng, Z.-L., Rosenthal, R., \& Rubin, D. B. (1992). Comparing correlated correlation coefficients. Psychological Bulletin, 111, 172-175.

Merrill, S. S., \& Verbrugge, L. M. (1999). Health and disease in midlife. In S. L. Willis \& J. D. Reid (Eds), Life in the middle: Psychological and social development in middle age (pp. 77-103). San Diego: Academic Press.

Mroczek, D. K., \& Kolarz, C. M. (1998). The effect of age on positive and negative affect: A developmental perspective on happiness. Fournal of Personality and Social Psychology, 75, 1333-1349.

Nolen-Hoeksema, S. (1987). Sex differences in unipolar depression: Evidence and theory. Psychological Bulletin, 101, 259-282.

O'Regan, M. C., \& Clow, A. (2004). Decreased pain tolerance and mood in recreational users of MDMA. Psychopharmacology. Special MDMA (ecstacy), 173, 446-451.

Pedersen, N. L., Plomin, R., McClearn, G. E., \& Friberg. L. (1988). Neuroticism, extraversion, and related traits in adult twins reared apart and reared together. Fournal of Personality E Social Psychology, 55, 950-957.

Ryff, C. D., \& Singer, B. H. (2001). Introduction: Integrating emotion into the study of social relationships and health. In C. D. Ryff \& B. H. Singer (Eds), Emotion, social relationships, and health (pp. 3-22). Oxford: University Press.

Salovey, P., \& Birnbaum, D. (1989). Influence of mood on health-relevant cognitions. Fournal of Personality $\mathcal{E}$ Social Psychology, 57, 539-551.

Stone, A. A. (2000). Self-reporting of physical symptoms. In A. A. Stone, J. S. Turkkan, C. A. Bachrach, J. B. Jobe, H. S. Kurtzman \& V. S. Cain (Eds), The science of self-report (pp. 297-298). Mahwah, NJ: Lawrence Erlbaum Associates.

Tennen, H., Suls, J., \& Affleck, G. (1991). Personality and daily experience: The promise and the challenge. fournal of Personality, 59, 313-338.

Tveito, T. H., Passchier, J., Duivenvoorden, H. J., \& Eriksen, H. R. (2004). Subjective health complaints and health related quality of life in a population of health care workers. Psychology and Health, 19, $247-259$.

Verbrugge, L. M. (1985). Gender and health: An update on hypotheses and evidence. Fournal of Health and Social Behavior, 26, 156-182.

Watson, D. (1988). Intraindividual and interindividual analyses of positive and negative affect: Their relation to health complaints, perceived stress, and daily activities. Foumal of Personality and Social Psychology, 54, 1020-1030.

Watson, D., \& Pennebaker, J. W. (1989). Health complaints, stress, and distress: Exploring the central role of negative affectivity. Psychological Review, 96, 234-254. 
Copyright of Psychology \& Health is the property of Routledge, Ltd.. The copyright in an individual article may be maintained by the author in certain cases. Content may not be copied or emailed to multiple sites or posted to a listserv without the copyright holder's express written permission. However, users may print, download, or email articles for individual use. 